\title{
Seasonal Movements of Atlantic Herring (Clupea harengus): Results From a Four Year Tagging Study Conducted in the Gulf of Maine and Southern New England
}

\author{
J. Kohl Kanwit and David A. Libby \\ Maine Department of Marine Resources, \\ P.O. Box 8, West Boothbay Harbor, ME 04575, USA. \\ Email: kohl.kanwit@maine.gov
}

Kanwit, J. K., and D. A. Libby. 2009. Seasonal movements of Atlantic herring (Clupea harengus): results from a four year tagging study conducted in the Gulf of Maine and Southern New England. J. Northw. Atl. Fish. Sci., 40: 29-39. doi:10.2960/J.v40.m577

\begin{abstract}
This paper presents results from a four year tagging effort on Atlantic herring (Clupea harengus) in the waters off the east coast of the United States. This study was designed to describe seasonal movements and evaluate new live capture methods for mobile gear using an aquarium codend. A total of 85561 Atlantic herring were tagged and released in two strata; the Gulf of Maine during the summer feeding/spawning period and Southern New England during the winter feeding period. The return rate, adjusted for reporting, was $2.6 \%$ and the patterns of returns largely reflected results from previous tagging studies in the US and Canada. The two main contributions of this work to the established body of herring tagging literature are: (1) the identification of current seasonal movements, including the migration of Atlantic herring from Southern New England in the winter to Nova Scotia in the summer, and (2) the implementation of a capture technique for midwater trawl gear and the ability this provided the researchers to successfully tag Atlantic herring on their winter feeding grounds as far south as Cape May, NJ.
\end{abstract}

Keywords: aquarium codend, Atlantic herring, migration, movement, tagging

\section{Introduction}

The Atlantic herring (Clupea harengus Linnaeus, 1758 ) is a pelagic species that occurs on both sides of the Atlantic Ocean, and ranges from northern Labrador to Cape Hatteras, NC, in the western Atlantic (Collette and Klein-MacPhee, 2002). On the east coast of the United States (US) herring have been exploited since preColonial times and a robust commercial fishery has persisted since the $19^{\text {th }}$ century, peaking in the late $1960 \mathrm{~s}$ and early 1970s. With an estimated biomass of one million metric tons ( $t$ ) for the Gulf of Maine/Georges Bank stock complex (TRAC, 2006), herring provide a major forage base for other fish species, marine mammals, and birds, as well as supporting the second largest commercial fishery on the eastern coast of the US. Landings from this fishery have averaged $100000 \mathrm{t}$ over the past several years, with an estimated value in excess of $\$ 25$ million (NMFS, 2006).

The Gulf of Maine/Southern New England Atlantic herring tagging initiative started in the summer of 2003 and continued through 2006. This study was designed to provide current information on the movements of the Gulf of Maine/Georges Bank Atlantic herring stock complex. Since the last large scale tagging projects in US waters 20-30 years ago (Stobo MS, 1983), the fishery evolved from using primarily fixed gear in in-shore waters to using mobile gear in off-shore waters almost exclusively (NEFMC, 1999). Furthermore, during the time of this study, the Georges Bank portion of the stock complex was considered fully recovered from its collapse in the 1980s (Reid et al., 1999). The objectives of the study were to: (1) implement an effective herring tagging project using mobile gear capture methods in the Gulf of Maine and Southern New England, (2) conduct a seeding study to estimate reporting rates from different industry sectors, (3) develop a means for adjusting tag returns based on catch and effort data, and (4) use the adjusted returns to describe movement and compare this to results from previous tagging studies.

\section{Materials and Methods}

In this study, tagging events and tag returns were categorized in the context of spatial and temporal strata. 
Five major spatial strata were defined in the Gulf of Maine/Bay of Fundy region: Nova Scotia (NS), New Brunswick (NB), the Gulf of Maine (GOM), Georges Bank (GB), and Southern New England (SNE; Fig. 1). The four temporal strata defined for this study were based largely on previous tagging work (Stobo MS, 1983) and are defined as: Spring Migration (SM: May-June), Summer Feeding/Spawning (SFS: July-October), Fall Migration (FM: NovemberDecember), and Winter Feeding (WF: January-April).

This tagging project was largely conducted in an opportunistic manner due to funding limitations and inconsistencies, as well as logistical challenges. For example, dedicated funding was received for one year of the study to conduct a comprehensive tagging program, however this funding was not continued in subsequent years. All releases presented in this paper occurred in the GOM during the SFS period and in the SNE during the WF period. These are both areas and periods when herring are assumed to have some seasonal residency related to where they are found. Tagging did not occur in the SM or FM periods because fish are known to be moving rapidly at these times and the resulting data would be of less value. Tagging in both spatial strata occurred each year between 2003 and 2006. Atlantic herring in pre-spawning condition were targeted for tagging in the GOM under the assumption that they were representa- tive of the spawning stock in that area. Groups of age three plus herring were targeted in the SNE assuming that they were representative of the spawning stock from which they originated.

\section{Marking techniques}

Two types of T-bar tags were used in this study. Tags made by Floy Tag Inc. (4616 Union Bay Place NE; Seattle, WA 98105), had an overall length of $6.0 \mathrm{~cm}$ and included the following information on a bright yellow, plastic sleeve: "MAINE DMR - \# \# \# \# \# \#". Tags produced by Hallprint PTY LTD (15 Crozier Rd. Victor Harbor; South Australia 5211) had an overall length of 6.5 $\mathrm{cm}$ included the following label on a bright pink, plastic sleeve: "\# \# \# \# \# \# \$1000 LOTTERY 207-633-9535 // PO BX 8 W BOOTHBAY ME 04575". All tags were imprinted with a unique identification number in sequential order. Both types of tags were applied using the Western States Supply Co. Mark III Tag Fast application gun fitted with stainless steel needles.

\section{Tagging events}

Tagging excursions were made on two classes of commercial fishing vessels; purse seiners and midwater trawlers. The purse seine vessels (three) ranged in size from $20-30 \mathrm{~m}$ and fished commercial seine nets, averaging $549 \mathrm{~m}$ long and $76 \mathrm{~m}$ deep with $2.9 \mathrm{~cm}$ mesh

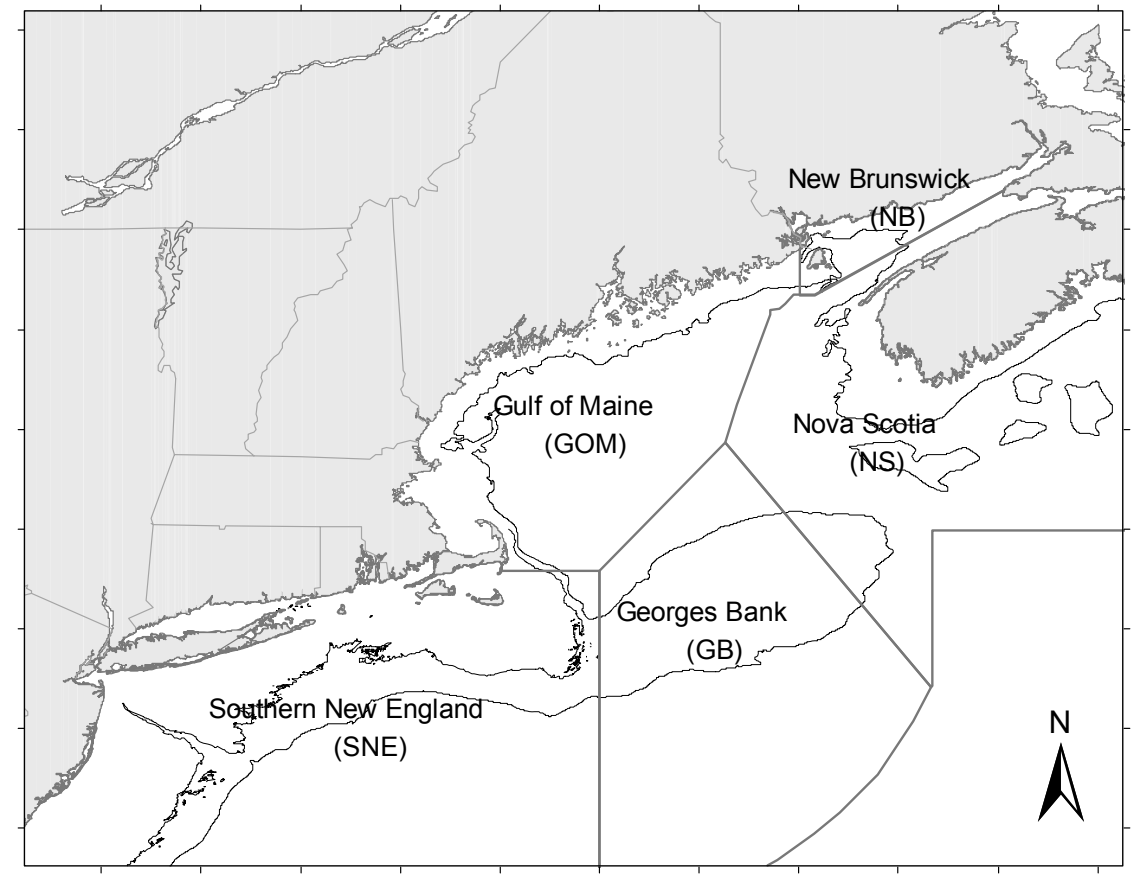

Fig. 1. Atlantic herring tagging project spatial strata. 
throughout. All tagging on purse seine vessels was undertaken during normal commercial fishing operations. Once a school of herring was encircled by the seine, the fish were dipnetted out as they swam along the perimeter of the net. The fish were removed from the seine well before they were "hardened", or concentrated in a small pocket of the net in preparation for pumping the fish onboard. Live herring were transferred to a holding tank with a controlled flow of fresh sea water (at a rate of $5 \mathrm{gal} / \mathrm{min}$ ) provided by a submersible pump. Fish were selected randomly and tagged after a cursory determination of condition. Fish that were judged to have less than $80 \%$ scale coverage or any indication of injury were discarded without a tag. Herring that appeared healthy and active had a conventional T-bar tag inserted between the interneural rays of the musculature directly below the dorsal fin on the left side. The herring were released on the non-working side of the vessel immediately after tagging.

The midwater trawl vessels (two) were 23-27 $\mathrm{m}$ and both fished a Swan Net pelagic midwater trawl net with 2.4-3.7 $\mathrm{m}$ mesh at the head rope grading down to 1.9 $\mathrm{cm}$ mesh in the codend. An aquarium codend, originally developed by the National Marine Fisheries Service (NMFS) for the capture of salmon smolts at sea was attached to the existing commercial herring net (Holst and McDonald, 2000). Tagging aboard midwater trawlers was carried out only when the vessel was under contract because of the gear modification involved. Tows were made as short as possible and targeted small aggregations of fewer than 1000 fish. A controlled flow of fresh seawater was introduced into the aquarium codend immediately after it was brought back onboard the vessel. Tagging was conducted as previously described. Since tagging onboard midwater trawl vessels frequently occurred during the day when visual predators were abundant (e.g. sea birds), the fish were released under a protective covering. This barrier floated on the surface of the water and allowed the fish to quickly escape before they were seen by avian predators.

\section{Project outreach and tag return incentives}

Extensive outreach efforts to inform the public were made throughout this project to encourage tag returns. A lottery system with one- $\$ 1000$ and two- $\$ 500$ prizes annually was established in addition to a small token for each returned tag (ball caps and T-shirts). The results of the lottery drawings were announced in fisheries publications and project bulletins. Many marine fish tagging projects in the Northeast have opted for the lottery approach in lieu of smaller, individual, monetary rewards, but project leaders agree that the comparative effectiveness should be evaluated (Tallack et al., 2004).

\section{Seeding study}

Tag seeding studies are routinely used in markrecovery projects in order to estimate the reporting rate (Campbell et al., 1992; Hampton, 1997). Seeding studies were conducted in the summer of 2004 to develop an estimate of the reporting rate for this project. Tags were surreptitiously seeded into landed herring catches while the fish were pumped off the fishing vessel and into transport trucks. Seven trials were conducted with four trials for fish going to a processor and three trials for fish going to lobster bait dealers. Each trial consisted of 10 individually tagged fish, a number settled on as representative of a real recapture event. If too few tagged fish were seeded into the catch, none of them may have been recovered, if too many were seeded into the catch, it would likely have changed the behavior of the workers at the processing plants and bait dealers. The experiment was terminated after the tagged fish were assumed to have passed completely through the processing and/or bait supply (one month minimum). The resulting estimates for reporting rates by sector were then applied proportionally to the actual tag returns. This was possible given that recovery data always included the sector from which the tag was returned. The actual tag returns numbers, adjusted for the reporting rate and referred to as "standard returns", were used in the subsequent catch/effort calculations and all other analyses presented in this paper.

\section{Data analysis}

The tagging data were first analyzed to generate time and distance plots. The distance between the release location and the recovery location was calculated using GIS software (Euclidean distance based on geometric coordinates). In cases where using a straight trajectory between the release site and the recovery location for an individual fish created a path over land, the most direct route around the landmass was measured. The number of days at large for each recovered fish was also calculated and then plotted against the distance each herring traveled.

Recaptures from fish tagging studies in the marine environment are usually dependant on commercial fisheries. The numbers of recaptures are related to where fishing activity occurs and to what extent the population is being exploited. Therefore, it is important to adjust tag returns based on effort before further analyses 
are conducted. Tag returns in this study were adjusted based on an equation developed by Hunt et al. (1999) that weights returns by catch and effort for a given area and year:

$$
A_{a, y}=C_{y} /\left(C_{a, y} E_{y}\right)
$$

where $A=$ adjustment factor, $C=$ percent of annual reported landings by management area, $E=$ reported annual exploitation rate by management area, $a=$ unit area, and $y=$ year.

There are no consistent estimates of $E$ or the catchability coefficient (q: $E=q f$ ) for the herring fishery for the areas or gear types considered in this study. Therefore, fishing effort (f) was used as a proxy for $E$. Fishing effort was defined in two ways; as the number of days fished and as the number of sets or tows made. Catch and effort data for the US fishery were obtained from NMFS Vessel Trip Reports, while Canadian data were obtained from the Department of Fisheries and Oceans (DFO). Effort adjustment factors, using the two measures of $f$ (days fished and sets made) were generated, and then applied to the standard tag returns from both release strata (GOM and SNE) for each year of the study. The adjustment factors were standardized to 1.0 for the area with the lowest calculated adjustment factor. The numbers of tag returns based on the adjustment factors were then compared to the number of standard returns by area. The standard tag returns were $\log$ transformed and regressed against the $\log$ of effort adjusted returns by area for days and sets. These comparisons were done using regression analysis since the data sets were not independent from one another. Each regression slope was tested against a slope of one by analysis of covariance. The results based on the effort adjustments from the two measures of $f$ were then compared to one another to see if one or the other was a better proxy for $E$.

\section{Results}

A total of 85561 herring were tagged in the GOM and SNE during the four year study (Table 1). Tagging occurred over 65 days, each day being considered a separate trip. In the GOM, 44 days were used to tag over 40000 fish. In the SNE, 20 days were used to tag more than 45000 herring. The total number of sets made was 189 , the majority of which were on contracted midwater trawl trips (134).

Tag returns from fish released in the GOM were recovered in each of the five defined spatial strata (Fig. 2). Recoveries occurred from as far east as Scots Bay in the Bay of Fundy to Hudson Canyon off the New York coast. Fish tagged in SNE were also recovered in all five of the spatial strata and the pattern of recoveries mirrored the range of the GOM returns from Scots Bay to Hudson Canyon (Fig. 3). There was no significant difference in return rates between fish marked with yellow tags and those marked with pink tags $\left(\chi^{2}=3.29 ; p<0.05\right.$; $\mathrm{df}=1)$. There was a small but significant difference in return rates from fish originally captured for tagging by purse seines versus midwater trawlers employing the aquarium codend $\left(\chi^{2}=5.20 ; p<0.05 ; \mathrm{df}=1\right)$. Fish captured and tagged from purse seines had a slightly higher rate of recovery.

\section{Seeding study}

Thirteen of the 70 tags seeded into the herring catch were recovered for an overall reporting rate of $18.57 \%$. Returns from the processing facilities were significantly higher $(33.33 \%)$ than returns from the bait sector $(7.50 \%$ : $\left.\chi^{2}=7.57 ; p<0.05 ; \mathrm{df}=1\right)$. The reporting rate was partitioned by sector and applied separately to the actual tag returns from processors $(N=139)$ and from the bait sector $(N=142)$, increasing the number of actual returns from $281(0.33 \%)$ to 2196 or $2.57 \%$. These "standard" returns were then used in all subsequent analyses.

\section{Seasonal movement}

Atlantic herring exhibit highly seasonal migrations, therefore it was appropriate to consider the tagging data in a temporal context. Fig. 4 plots the distance traveled from the original tagging location in the GOM during the SFS against the time at large for individual fish. With a

TABLE 1. Number of herring tagged by year, spatial and temporal stratum.

\begin{tabular}{|c|c|c|c|c|c|c|}
\hline \multirow[b]{2}{*}{ Spatial strata } & \multirow[b]{2}{*}{ Temporal strata } & \multicolumn{4}{|c|}{ Year } & \multirow[b]{2}{*}{ Total } \\
\hline & & 2003 & 2004 & 2005 & 2006 & \\
\hline $\begin{array}{l}\text { Gulf of Maine } \\
\text { (GOM) }\end{array}$ & $\begin{array}{l}\text { Summer Feeding/Spawning } \\
\text { (SFS: July-October) }\end{array}$ & 15275 & 13475 & 5300 & 6100 & 40150 \\
\hline $\begin{array}{l}\text { Southern New } \\
\text { England (SNE) }\end{array}$ & $\begin{array}{l}\text { Winter Feeding } \\
\text { (WF: January-April) }\end{array}$ & 4536 & 5875 & 20000 & 15000 & 45411 \\
\hline Total & & 19811 & 19350 & 25300 & 21100 & 85561 \\
\hline
\end{tabular}




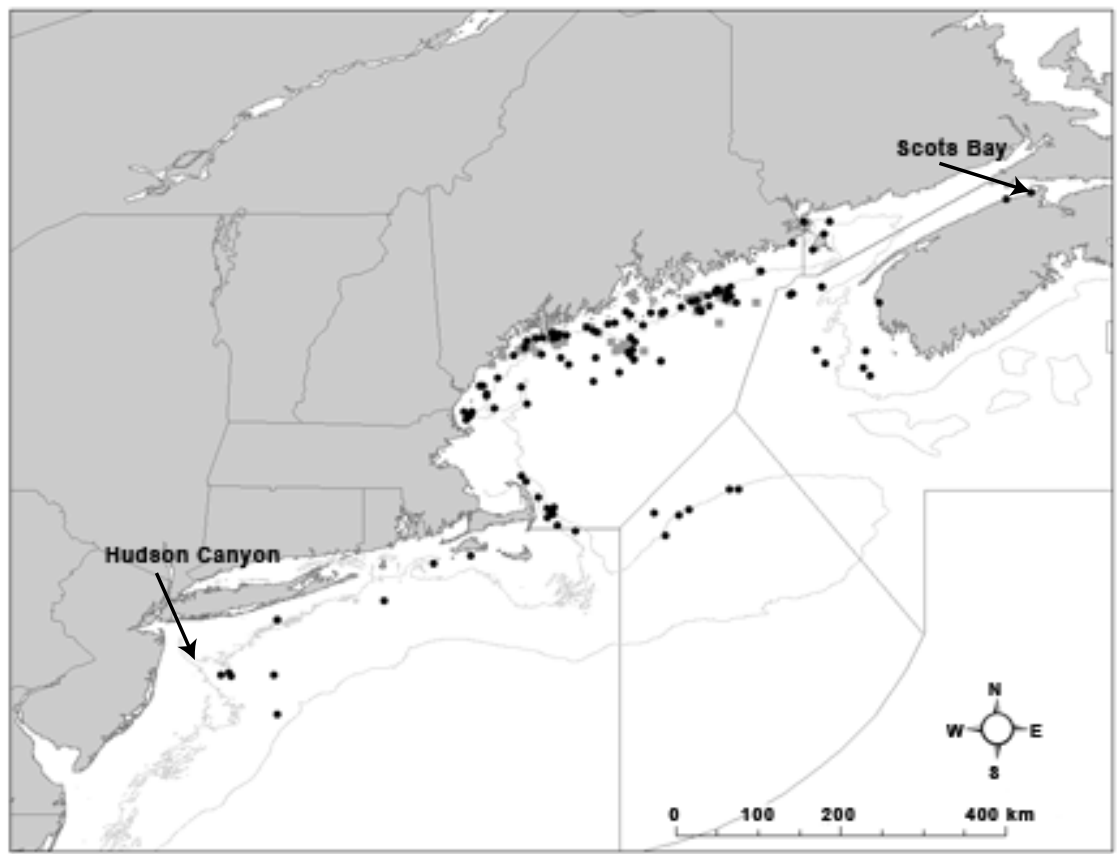

Fig. 2. Tagging locations (gray dots) and returns (black dots) from Atlantic herring released in the GOM during the SFS stratum.

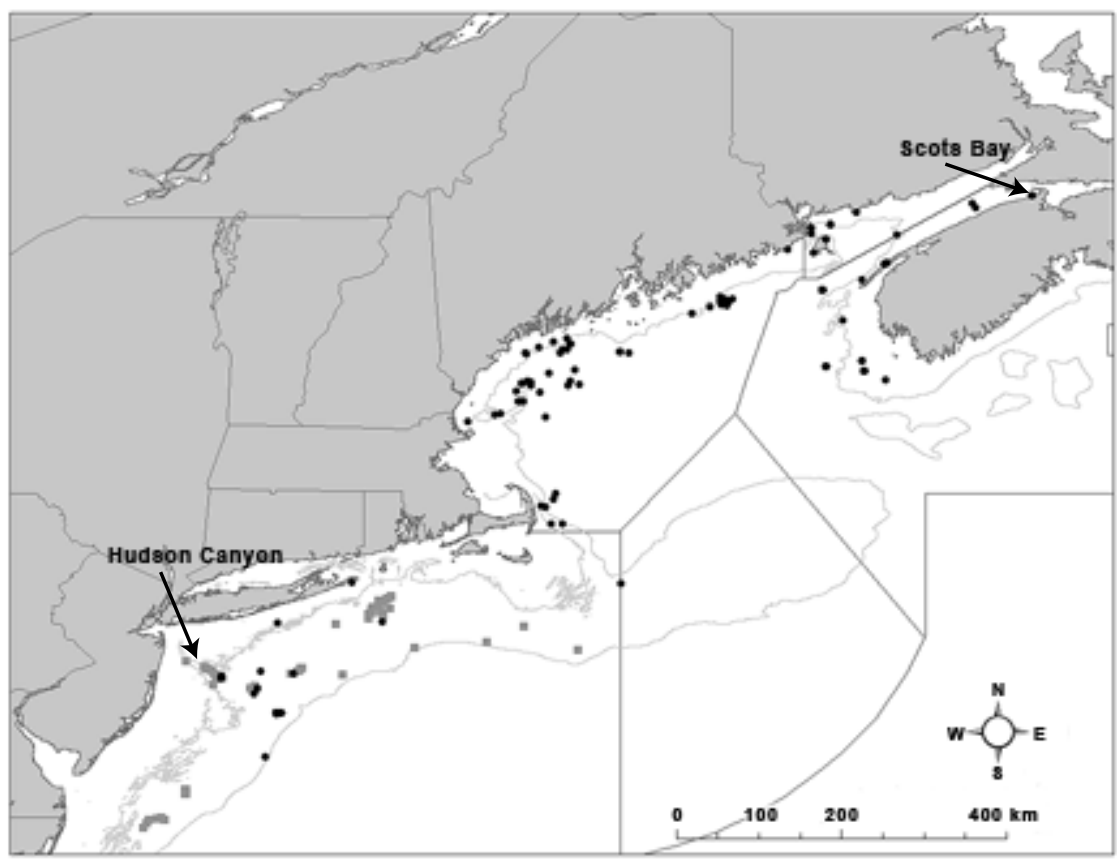

Fig. 3. Tagging locations (gray dots) and returns (black dots) from Atlantic herring released in SNE during the WF stratum. 


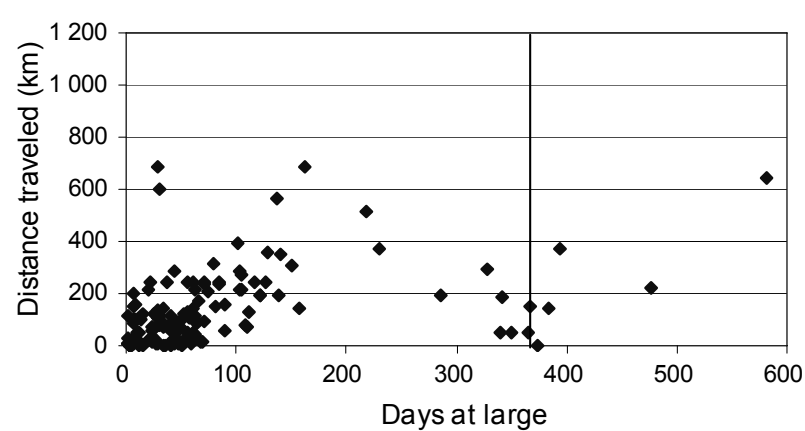

Fig. 4. Time at large and distance traveled for fish released in the GOM (vertical line represents 1 year from release).

few exceptions, recoveries show a clear pattern of short term residency during the SFS followed by longer distance migrations with the passage of time through the FM, WF and SM. Recoveries of fish tagged in the GOM were made close to the original tagging locations in the SFS around one year after release. Only six recaptures were made more than one year at large, but these recoveries seem to mirror the same migratory patterns with fish being recaptured further from their release locations. The fish released in the GOM traveled an average of $134 \mathrm{~km}$ with a minimum of $1 \mathrm{~km}$ and a maximum of $684 \mathrm{~km}$.

Most of the fish released in SNE during the WF left the tagging area comparatively quickly. Recaptures made in the WF 200+ days after the initial tagging were generally near the original release site (Fig. 5). Returns showed a pattern of moving away through the SM and SFS and being returned closer to the release locations in the FM and WF. Only three tags were returned with adequate recovery information more than one year after release, but showed a similar pattern as the GOM fish. The fish released in SNE traveled and average of $362 \mathrm{~km}$ with a minimum of $2 \mathrm{~km}$ and a maximum of $1008 \mathrm{~km}$.

\section{Tag return adjustments}

The standard tag returns and the returns adjusted for catch and effort were compared to assess how the catch and effort adjustments might affect observed patterns of movement between areas. The results of covariance analysis indicated that there were no overall significant differences between the adjustments based on the two measures of effort used (Table 2). Despite the fact that the regression analyses indicated that the adjusted number of tags were larger than the standard number of tags based on both measures of effort, there were few significant differences between the standard returns and the returns adjusted by either sets or days.

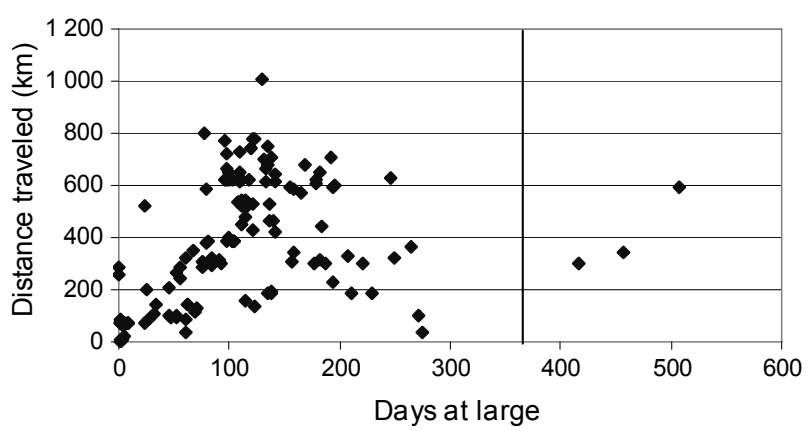

Fig. 5. Time at large and distance traveled for fish released in SNE (vertical line represents 1 year from release).

For fish released from GOM, the majority of fish were recaptured in the GOM (Fig. 6). Recoveries of fish in the GOM for all years combined averaged $68 \%$ based on the actual tag return numbers, but averaged $82 \%$ based on standard returns. When the adjustment factors for effort were used, the recoveries in GOM were consistent on an annual basis (Fig. 6). Migration to SNE from the GOM was also stable, averaging $9 \%$ for the actual return numbers over all years, $4 \%$ for the standard return numbers and 6-8\% when adjusted for effort. Returns from GB consistently averaged between $8-9 \%$ for actual returns and all adjusted returns with the exception of the adjustment made using days (6\%). Returns from NS surprisingly accounted for a sizable percent of the actual recoveries (11\%) but were reduced by all adjustment factors (4-5\%). Migration to NB only accounted for a small portion of the returns (4\%) and was similarly reduced by all adjustment factors to around $1 \%$.

Tag returns for fish released from SNE were also distributed among all the strata (Fig. 7). The actual returns, averaged over all years showed that one-third of fish moved to the GOM while the standard returns averaged $55 \%$ and the effort adjusted rates averaged $62 \%$ and $49 \%$. Actual returns average $23 \%$ in SNE, while all the adjusted returns indicated an average between $18-21 \%$ (Fig. 7). All returns from GB indicated $4 \%$ movement into this stratum. There was a considerable difference between the actual and adjusted returns from NS. Actual returns indicated $33 \%$ of tagged fish moved to NS while the standard and adjusted returns estimated between 14\% and $23 \%$. NB also showed actual returns reduced by all of the adjustment factors from $6 \%$ to $2-3 \%$.

\section{Discussion}

Results related to movement patterns from this study largely reaffirm conclusions made by several previous 
TABLE 2. Probability values from analysis of covariance by spatial strata and year comparing standard returns and adjusted returns. Underlined values show significant slopes.

\begin{tabular}{|c|c|c|c|c|c|c|c|c|}
\hline & \multicolumn{4}{|c|}{ Gulf of Maine } & \multicolumn{4}{|c|}{ Southern New England } \\
\hline & 2003 & 2004 & 2005 & 2006 & 2003 & 2004 & 2005 & 2006 \\
\hline standard/days & 0.965 & 0.369 & 0.851 & $\underline{0.000}$ & 0.370 & 1.000 & 0.374 & $\underline{0.013}$ \\
\hline standard/sets & 0.557 & 0.622 & 0.502 & $\underline{0.001}$ & 0.081 & $\underline{0.020}$ & 0.944 & $\underline{0.005}$ \\
\hline days/sets & 0.120 & 0.510 & 0.100 & $\underline{0.028}$ & 0.050 & 0.228 & 0.524 & 0.076 \\
\hline
\end{tabular}

herring tagging projects in the US and Canada (Almeida and Burns, MS 1978; Burns, MS 1977; ICNAF, 1976; Speirs, MS 1977; Waring, MS 1981; Creaser and Libby, 1988; Stobo, MS 1983; Waters and Clark, MS 2004). Two novel elements of this study are the adaptation and implementation of an aquarium codend to capture live herring using midwater trawl gear and the ability this technique gave the investigators for tagging herring in SNE during the winter. While some tagging was accomplished in winter months by previous studies (Waring, MS 1981), the releases were limited in time and space. Tagging in SNE in this project during the WF period was repeated over four years and extended as far south as Cape May, NJ.

\section{Mark-recovery experiments}

The results from this study reinforce that markrecovery experiments can be a useful tool in studying Atlantic herring movement, specifically in the context of the offshore dominated fishery in areas where herring behavior and distribution require a capture method based on midwater trawl gear. Obtaining healthy herring has always been a challenge for tagging projects. In the past, many herring tagging projects relied on fish caught by weirs and stop seines close to shore (Speirs, MS 1977; Chenoweth et al., MS 1980; Creaser et al., 1984; Creaser and Libby, 1988). These gear types were ideal for tagging because the herring are allowed to school freely within the enclosure until the catch was harvested. This provided an opportunity for researchers to apply tags on healthy fish, near-shore in a relatively controlled environment. There is virtually no remaining fixed gear fishery for Atlantic herring in US waters and the herring fishery is now dominated by mobile gear fishing vessels employing purse seines and midwater trawls (NEFMC, 2006). Obtaining healthy herring from these gear types is much more difficult because they are used offshore in more variable conditions. Purse seines are not effective in deeper offshore water unless the herring school or "bunch up" and rise to the surface during their diurnal feeding activities. Once captured, these herring can only be accessed by tagging personnel if the school circles around the perimeter of the seine within reach of dip nets deployed from the fishing vessel. Experience in the field showed that the fish cannot be netted more then once and they cannot be kept for longer than one hour despite the amount of circulating water used in the holding tanks. Using midwater trawls to obtain live herring in an area and time of year when they do not "bunch up" posed a challenge because the commercial nets are large, the twine is abrasive and the herring are normally compressed in the codend during the capture process. The aquarium codend provided a contained, still pocket of water where the herring could collect while the net was being fished. This implementation of the aquarium codend for herring tagging was critical to the study as it allowed tagging activities to occur where temporally and geographically necessary to develop a comprehensive picture of herring movement in the northeastern US.

That returns were slightly higher from fish captured for tagging using a purse seine is likely due to the fact that these fish were all released in GOM, an area of high fishing effort and presumed limited mixing during SFS. Conversely, most of the fish captured for tagging using midwater trawl gear fitted with an aquarium codend were released in SNE, an area of much lower fishing effort and presumed high mixing of different stock components. This is reflected by how quickly fish were recaptured from the two spatial strata; the average days at large of fish released in GOM was 94 days versus an average of 116 days for fish tagged in SNE. Fish tagged in the GOM were recaptured in GOM during the same SFS period as they were released $57 \%$ of the time. In comparison, fish tagged in SNE were recaptured in the SNE during the same WF period as they were released only $19 \%$ of the time.

\section{Tag return rate}

Achieving adequate return rates in any tagging project on an open population is difficult, but particularly so in the context of the modern Atlantic herring fishery. Past tagging studies in the US reported actual return rates occasionally as high as six percent (Creaser and 

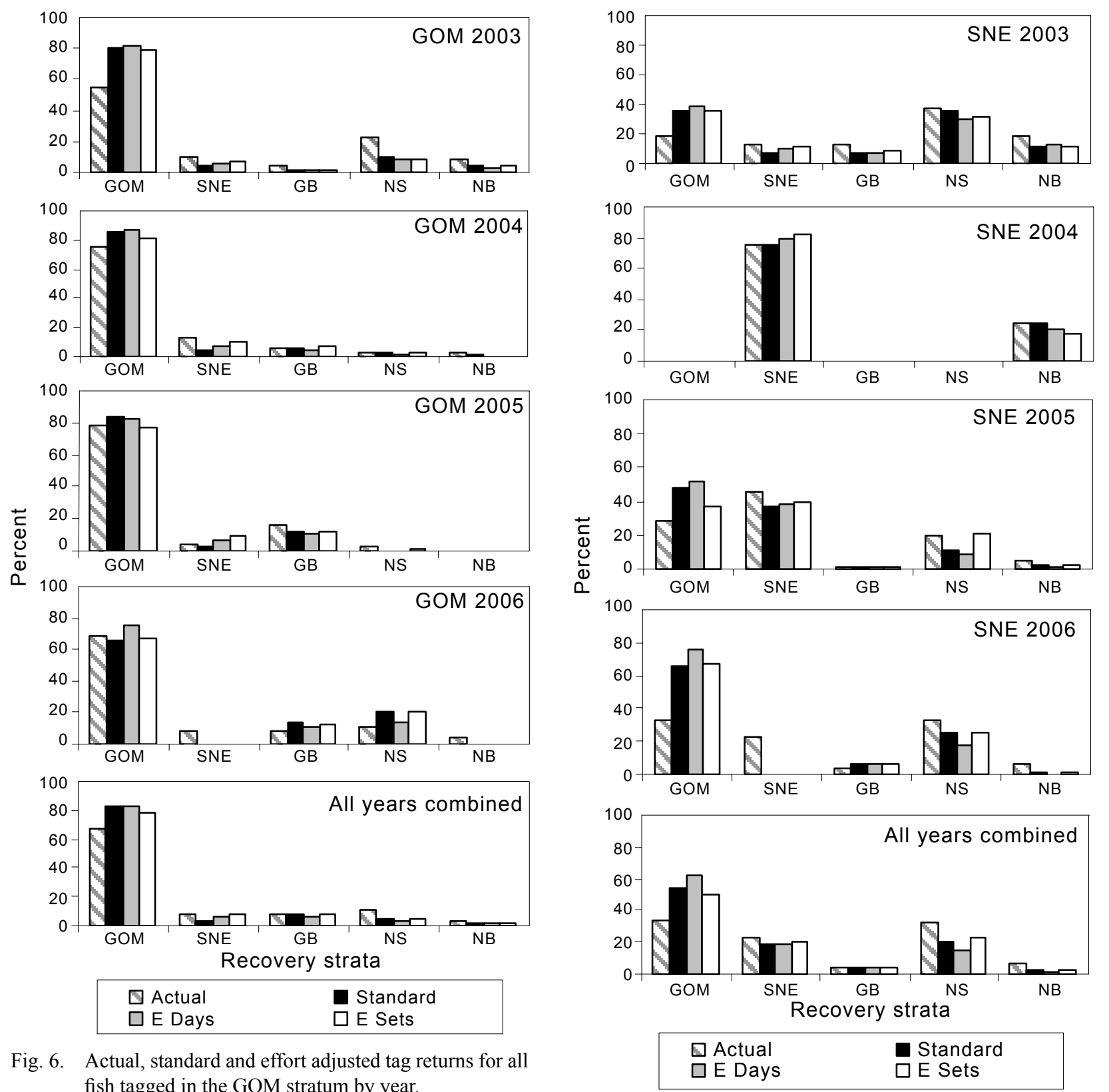

Fig. 6. Actual, standard and effort adjusted tag returns for all fish tagged in the GOM stratum by year.

Libby, 1988), but averaged between one and three percent. These comparatively high return rates were likely a result of several factors such as: fish were in excellent condition prior to tagging since they were most frequently obtained from fixed gear as previously discussed; the vast majority of recaptures were made shortly after the fish were released and in the same geographic vicinity; and the overall herring population was in a depressed state with the collapse of the Georges Bank component so a larger proportion of fish were being tagged. Finally, these studies were all conducted at a time when $80 \%$ of the herring catch went to canneries. The processing fa-

Fig. 7. Actual, standard and effort adjusted tag returns for all fish tagged in the SNE stratum by year.

cilities provided an increased opportunity for the tagged fish to be seen, because every herring was handled by a plant worker while they were sorted, cut and packed (Tupper et al., 1998). Results from the seeding study conducted as part of this project, support this finding as it proved that recoveries from processors are much higher than from the bait sector.

This tagging project occurred in the context of a changed fishery from 20-30 years ago and recovered 
stock status (Overholtz, 2002). The mobile gear fishing fleet has dominated the fishery since the 1970s and this fleet covers a broader geographic area, pursuing herring throughout the year. This means that short term recaptures within a small geographic area are less likely, resulting in lower actual return rates than were realized from previous studies. The sheer magnitude of the US Atlantic herring stock size and the relatively low fishing mortality rate (TRAC, 2006) requires a large number of fish to be tagged to realize even a small number of returns. This is an especially important consideration in SNE during the WF period when it is assumed that all of the US coastal complex stock components intermix. Statistically, more than 60000 fish should have been tagged in the SNE annually in order to release marked fish in proportion to the population abundance and distribution. This goal was logistically impossible for this project. Releases in SNE during this project averaged 11 000 annually over the four year period and were as low as 4536 in the first year.

The market structure of the US herring fishery has also changed, from processor dominated to the majority of landings going to the bait industry. In 2006, between $55 \%$ and $60 \%$ of the catch went to lobster bait dealers. Tagged herring are difficult to recover from lobster bait because the first opportunity to see a tagged fish is when the crew of the lobster boat fills bait bags between hauling strings of traps. Recoveries are reliant on nonherring fishermen to see the tag, be aware of the project and have a desire to report the recovery. In addition, shore-side processors and the catcher vessels themselves employ modern mass handling techniques that provide only limited opportunities to see tagged fish. Almost all of the herring that comes ashore is pumped from the net onto the boat, then pumped into a truck and then into a processing plant or bait house.

The standard returns used in this study attempted to quantify the inconsistencies in people seeing and reporting tags throughout the fishery. The adjustment made for the bait sector is considered to reflect the ability of people to see a tag, their motivation to report the tag and their understanding of the importance of the research program and how it ties into their own fishery. The adjustment made for returns from processors is likely a reflection of the ability of workers to see a tagged fish as it moves though an automated plant. Anecdotal information from our program, as well as one that ran simultaneously in New Brunswick and Nova Scotia, suggests that the $\$ 1000$ lottery provided a high incentive for plant workers in both Canada and the US to return all tags they found. Since almost $100 \%$ of the herring caught in Canada goes to processors, we assumed the processor reporting rate was accurate and the general "willingness" of Canadians to send in tags more than US workers was not an additional factor influencing returns.

\section{Seasonal movement}

Atlantic herring are pelagic fish capable of long distance movements in very short periods of time (Sinclair and Iles, 1985). For example, one herring released in SNE during this study was returned 23 days later from the coast of Nova Scotia, a calculated distance of over $520 \mathrm{~km}$. While results from this tagging study largely mirror findings from previous tagging projects, they also indicate that there is appreciable movement of herring tagged in US waters off Rhode Island, New York and New Jersey during the winter months to Canadian waters in the summer months.

Tag deployments in SNE were variable because they relied on contracting a vessel for dedicated trips. Returns from SNE releases confirmed some presumed movement patterns and possible stock intermixing. Predictably, a large proportion of the returns came from the GOM in SFS where the bulk of fishing activity occurred in the four years of the study. The actual and adjusted results also indicated a large portion of the fish tagged in SNE remained or returned to SNE in the WF period in two of the four years. The variability of returns from fish tagged in SNE are likely due to the fluctuating number of releases especially in years of very low releases. However, the most important finding was the apparent movement of fish from SNE in the WF to NS in SFS. On average, 20\% of fish tagged in SNE were returned from NS, adjusted to $14-23 \%$ based on the catch/effort equations. The results of this study call into question the long standing assumption that the US coastal complex does not intermix to any meaningful extent with the NS stock.

Fish released in the GOM showed a relatively consistent pattern of recoveries including convincing evidence that stage 4+ fish remain in GOM and/or return to GOM during the SFS period. Interestingly, several prior tagging studies reached the same conclusion but some tied the apparent residency/fidelity directly to Jeffreys Ledge (Waring, MS 1981). No fish were tagged during the four years of this study on Jeffreys Ledge because herring were not observed in that area in substantial numbers during the SFS period. Whether this represents a permanent shift to the east in preferred spawning grounds and feeding areas or indicates a change in the inshore GOM stock abundance is unknown. 
There is also evidence from GOM tagged herring that some of the fish captured in the GOM are actually part of the NS spawning component. Several recaptures of spawning or pre-spawning herring originally tagged in the GOM were made in 2003, 2004 and 2006 on the fishing grounds of Nova Scotia (Scots Bay and German Bank) in the SFS period. Although adjusted to an average of 5\%, these results are noteworthy, apparently indicating that some amount of NS herring migrate through the GOM in the early summer months. These results coupled with data from fish tagged in the SNE would imply that the NS herring migrate through GOM after spending the WF period in SNE. Further evidence of this is also demonstrated by the tag returns from fish tagged on spawning grounds in Nova Scotia by DFO and recovered in the SNE during the WF period (Waters and Clark, MS 2004; C. L. Waters, pers. comm., 2006).

\section{Future research needs}

Atlantic herring is one of the most studied marine fish species in the world (Whitehead, 1985). This is due in part to their tremendous current and historical commercial importance to countries on both sides of the Atlantic and their role as a principal forage fish for various species of animals. Despite the vast amount of literature on the biology of Atlantic herring, a great deal about their population structure is still unknown. The stock structure in the western Atlantic is not completely understood which hampers management of the resource. The results presented in this paper are just a start toward defining the migration patterns and the degree of movement by Atlantic herring between Canada and the US.

\section{Acknowledgements}

We would like to thank the Northeast US herring industry, specifically the captains of the fishing vessels: David Reingardt, Mark Bichrest, Danny Fill, Steve Gough and Barry Matthews, the Maine Department of Marine Resources, the University of Maine, School of Marine Sciences and the Northeast Consortium for providing funding to carry out this research. We would also like to thank Yong Chen, Phil Yund and Gary Melvin, for their contributions to this manuscript.

\section{References}

ALMEIDA, F. P., and T. S. BURNS. MS 1978. Preliminary results of the International Tagging Program conducted on the northeast coast of the United States in 1977. NEFC, Lab. Ref. Doc. NMFS; No. 78-07.

BURNS, T. S. MS 1977. Preliminary results of the International Herring Tagging Program conducted on Georges Bank and Jeffreys Ledge. ICNAF Working Paper, 77/IV/10.

CAMPBELL, R. P., T. J. CODY, C. E. BRYAN, G. C. MATLOCK, M. F. OSBORN, and A. W. GREEN. 1992. An estimate of the tag-reporting rate of commercial shrimpers in two Texas bays. Fish. Bull., 90: 621-624.

COLLETTE, B. B., and G. KLEIN-MACPHEE. (Eds.). 2002. Bigelow and Schroeder's Fishes of the Gulf of Maine. Third Edition. Smithsonian Institution Press, Washington, DC, $748 \mathrm{p}$.

CHENOWETH, S. B., M. HUNTER, and G. SPEIRS. MS 1980. Seasonal migrations and recruitment patterns of juvenile herring in the Gulf of Maine. ME Dept. Marine Resources Res. Ref. Doc. 80/14.

CREASER, E. P., D. A. LIBBY, and G. D. SPEIRS. 1984. Seasonal movements of juvenile and adult herring, Clupea herengus, tagged along the Maine coast. J. Northw. Atl. Fish. Sci., 5: 71-78.

CREASER, E. P., and D. A. LIBBY. 1988. Seasonal movements of juvenile and adult herring (Clupea harengus harengus L.) tagged along the Maine and New Hampshire coasts in 1976-82. J. Northw. Atl. Fish. Sci., 8: 33-42.

HAMPTON, J. 1997. Estimates of tag-reporting and tag-shedding rates in a large-scale tuna tagging experiment in the western tropical Pacific Ocean. Fish. Bull., 95: 68-79.

HOLST, J. S., and A. MCDONALD. 2000. Fish-lift: A device for sampling live fish with trawls. Fisheries Research, 48: 87-91. doi:10.1016/S0165-7836(00)00116-8

HUNT, J. J., W. STOBO, and F. ALMEIDA, 1999. Movement of Atlantic cod, Gadus morhua, tagged in the Gulf of Maine area. Fish. Bull., 97: 842-860.

ICNAF REDBOOK. 1976. Report of the Standing Committee on Research and Statistics, App. II. Report of the Herring Working Group. Int. Comm. N. Atl. Fish., Dartmouth, NS. Aug. 1976.

NEFMC. 1999. Final Atlantic Herring Fishery Management Plan. Vol. 1. http://www.nefmc.org/herring/fmp/section_1.PDF

2006. Amendment 1 to the Fishery Management Plan for Atlantic Herring. Vol. 1. http://www.nefmc.org/ herring/planamen/final_herring_a1.htm

NMFS. 2006. Commercial Fisheries Landings Statistics Web Page; http://www.st.nmfs.gov/st1/commercial/. (page visited on 07/23/08)

OVERHOLTZ, W. J. 2002. The Gulf of Maine-Georges Bank Atlantic herring (Clupea harengus): spatial pattern analysis of the collapse and recovery of a large marine fish complex. Fisheries Research, 57: 237-254. doi:10.1016/ S0165-7836(01)00359-9

REID, R. N., L. M. CARGNELLI, S. J. GRIESBACH, D. B. PACKER, D. L. JOHNSON, C. A. ZETLIN, W. W. MORSE, and P. L. BERRIEN. 1999. Essential Fish Habitat Source Document: Atlantic Herring, Clupea harengus, Life History and Habitat Characteristics. http://www.nefsc.noaa.gov/publications/tm/tm126/ tm126.pdf

SINCLAIR, M., and T. D. ILES, 1985. Atlantic herring (Clupea harengus) distribution in the Gulf of Maine - Scotian Shelf area in relation to oceanographic features. Can. J. Fish. Aquat. Sci., 42: 880-887. doi:10.1139/f85-112

SPEIRS, G. D. MS 1977. Herring tagging in the western Gulf 
of Maine. ICNAF Res. Doc. 77/50.

STOBO, W. T. MS 1983. Annex 2. Report of ad hoc working group on herring tagging. NAFO Sci. Counc. Rep. 83/ $\mathrm{VI} / 18$.

TALLACK, S. M. L., P. RAGO, S. CADRIN, and J. HOEY, 2004. A workshop to review and evaluate the design and utility if fish mark-recapture projects in the Northeast US. NOAA Fisheries Res. Doc. http://www.codresearch.org/ WS/PROCEEDINGS_Fish_M-R_Workshop_Oct 2004. pdf

TRAC. 2006. Gulf of Maine-Georges Bank Herring Stock complex. TRAC Status Report 2006/01, 7 p. http://www.mar. dfo-mpo.gc.ca/science/trac/TSRs\%5CTSR_2006_01_E. pdf (page visited on 1/15/06)

TUPPER, M. H., V. C. ANTHONY, S. B. CHENOWETH, and
H. A. MACCLUEN. 1998. Biology and Assessment of Gulf of Maine Herring Stocks. Report Commissioned by the Gulf of Maine Aquarium.

WARING, G. MS 1981. Results of the international herring tagging program conducted by USA in the Gulf of Maine, Georges Bank and contiguous waters from 1976-1978. NAFO SCR Doc. No. 122, Serial No. N428, 24 p.

WATERS, C. L., and K. J. CLARK. MS 2004. Summary of the Weir Herring Tagging Project, with an Update of the HSC/PRC/DFO Herring Tagging Program. DFO Canadian Stock Assessment Secretariat Res. Doc. 2004/032, $44 \mathrm{p}$.

WHITEHEAD, P. J. P. 1985. King herring: his place amongst the clupeoids. Can. J. Fish. Aquat. Sci., 42 (Suppl. 1): 3-20. 